\section{ABSORPTION OF WATER BY THE LEAVES OF PLANTS}

THE experiments of Boussingault, referred to in NATURE, vol. xviii. p. 672, find a fitting sequel in those of the Rev. G. Henslow, detailed in a paper read before the Linnean Society on Norember 7. Although gardeners universally maintain that growing plants have the power of absorbing water through their leaves, both in the liquid and the gaseous form, in addition to the power of suction through the roots, yet the contrary theory has been in favour during recent years among vegetable physiologists. The first recorded experiments of any value on the subject were about the year 1727 , by Hales, ${ }^{1}$ as described in his "Statical Essays;" the conchusion to which he came being that "it is very probable that rain and dew are imbibed by vegetables, especially in dry seasons." This result was confirmed by Bonnet in 1753. A century later, however, in 1857 , Duchartre, experimenting on the absorptive power of plants, came, after considerable wavering, to the conclusion that rain and dew are not absorbed by the leaves of plants. This opinion has been, with but little exception, held by all physiologists during the last twenty years, notably by De Candolle and Sachs; the explanation offered of the fact that withered plants revive when placed in moist air or when the leaves are moistened, being that transpiration is thus stopped, or is more than counterbalanced by the root-absorption. In his "Text-book of Botany" (English edition, p. 613), Sachs says:- "When land-plants wither on a hot day, and revive again in the evening, this is the result of diminished transpiration with the decrease of temperature and increase of the moisture in the air in the evening, the activity of the roots continuing; not of any absorption of aqueous vapour or dew throngh the leaves. Rain arain revives withered plants, not by penetrating the leaves, but by moi-tening them, and thus hindering further transpiration, and conveying water to the roots, which they then conduct to the leaves. McNab has, however, proved that leaves to transpire, even in a moist atmosphere, provided they are exposed to the action of light.

The results of Mr. Henslow's experiments, extending over several years, are altogether in accordance with those of boussin. gault, and may be considered to set the question of the absorbent power of the leaves of plants completely at rest. The following are the chief conclusions arrived at:- $-\mathbf{r}$. The absorption of water by internodes. The experiment consisted of wrapping up one or more internodes of herbaceous plants in saturated b) lotting-paper and in noticing the effects. As a rule the leaves on the shoots rapidly perished, showing that transpiration was too great for the supply. The stems, however, kept fresh for different periods up to six weeks. 2. Absorption by leaves, to see how far they could balance transpiration in others on the saine shoot. The general result is that as long as the leaves remain green and fresh in or on water, they act as absorbents, but that the leaves in air keep fresh or wither according as the supply equals or falls short of the demand. 3. To test how far leaves on a shoot can nourish lower ones on the same shoot. It appears that it is quite immaterial to plants whether they be supplied from witter by the absorbing leaves being above or below those tratspiring. Water flows in either direction equally well. 4 Leares floating on water. It was found that one part of a leaf cnn nourish another part for various periods, though the edges out of water died first. 5. Absorption of dew. A long series of cut leaves and shoots were gathered at 4 P.M., then exposed to sun and wind for three hours, then carefully weighed and exposed all night to dew. At 7.30 A.M., after having been dried, they rere weighed again, and all had gained weight and quite recovered their freshness, proving that slightly wetted detached portions do absorb dew. 6. Imitation dew. Like results followed from using the "spray," by which dew could be exactly imitated. 7 . Plants growing in pots and of which the earth was not watered, were kept alive by the ends of 'one or more shoots being placed in water; e.g., Minnulus moschatus not only grew vigorously and developed axillary buds into shoots, but even blossomed.

By these interesting experiments the physiological botanist is again placed in harmony with the gardener who syringes his plants, not merely for the purpose of washing off dust and insects, but in order to facilitate the actual absorption of water by the surface; and with the field botanist, who sprinkles the plants in his vasculum with water to keep them fresh till he

In his " Geschichte der Botanik," pp. 5x5-521, Sachs gives an admirable epitmme of the great service rendered to the progress of botanical science by the researches of this eminent botanist and physicist. reaches hone. The fact which now seems established begond all doubt by the observations of Darwin and others, that certain plants have the power of absorbing through their leaves and digesting the remains of animal substances, also implies, as a necessary corollary, the absorbent power of leaves for certain liquid or gaseous substances. In connection with this subject sufficient attention has perhaps not been attracted to the observations of Prof. Calderon, as detailed in a paper printed at Madrid, in English ( I877), entitled, "Considerations on Vegetable Nutrition." Calderon's statements-which, however, require at present to be confirmed by other observers-are to the effect that plants have the power of absorbing the nitrogenous oryanic matter which is constantly floating in the air, and that, if air be deprived of all organic matter, it is unable to sustain vegetable life, all the physiological functions of plants being then suspended.

A. W. B.

\section{UNDERTONES}

THESE formed the subject of a lecture delivered by $\mathrm{Her}^{\mathrm{r}}$ Auerbach before the meeting of Naturalists at Casse this year.

The term "undertones," he pointed out, is an extension of the nomenclature which denotes certain accompanying tones of a given note "overtones." Undertones may be observed in the following way:-If a struck tuning-fork be set on a soundboard, a tone is heard sounding strongly, which before was little perceptible. The stem of the fork makes longitudinal vibrations, which, by action on the sounding-board (a very thin one), generate transverse vibrations, and these spread over the large surface of the plate: Should the tone of the board only differ in intensity from that of the fork, the vibrations executed by the stem of the tuning-fork must be small; it is otherwise, however, when the vibrations exceed a certain amount.

Herr Auerbach demonstrated his observation with a tuningfork giving the $\mathrm{A}$ of a violin, and so 435 vibrations per second. When he placed the vibrating fork firmly on a sonud-board, the tone was heard distinctly at a distance. When, however, he brought the tuning-fork, struck very vigorously, into very light contact with the plate, there was heard the lower octave of the fork's tone. With other materials, which were not then at his command, he could produce also the lower fifth of the lower octave, and the lower fourth of this tone, i.e., the double octave of the fork's tone. The vibration numbers of these resonance tones are $\frac{1}{2}, \frac{1}{3}, \frac{2}{4}, \&$ c., of that of the tuning-fork's tone, i.e., the resonance-tones form the series of the harmonic zundertones.

With regard to the mode of occurrence of these tones, Her: Auerbach said this: "To prove to you, first of all, that the strength of the vibrations is the fundauiental condition of the phenomenon, I will once more make the experiment, and continue it longer. You heard first, again, the lower octave; but then the tone sprang over into the higher, so that it became identical with the proper tone of the tuning-fork. Consider this result along with the fact that the vibrations of the fork rapidly diminish; remember, too, that it is only when the fork is vigorously struck and lightly placed on the plate that the undertones occur, and you will see that the cause of the phenomenon lies in the amplitude of the vibrations."

Herr Auerbach further supposes that the resonance-surface of the plate, being imperfectly elastic, follows the movements of the stem of the fork immediately downwards indeed, but not up. wards; an interval then occurs which only disappears on the next passage downwards of the stem. If the retardation be a smail one, the plate, at the moment of meeting the stem a second time, has nearly completed a vibration. If, however, the retardation be great, the undertones arise (as the lecturer showed graphically) from the combination of the vibrations of the stem and the plate. The stem-end, i.e., in this latter case, is no longer an unconditionally free end, but its freedom is a periodic function of the time, and this period is twice as great as that of the tuning-fork vibrations. "That the undertones arise in consequence of internal friction, was easy to see a priori: what the experiments have shown and explained is the interesting fact, that precisely the harmonic undertones are produced; that is a consequence of the fact that the resonance is the action of a periodic force, and so, in a certain sense, a discontinuous phenomenon, otherwise the undertones must form a continuous series, which is not the case."

See Niture, vol. xv. p. 108. 
"It is obvious," he continues, "that the description given of the phenomenon is incomplete, for ductility, elasticity, variation of the resonance-plate, \&c., co-operate to produce a more complicated phenomenon. I have tried a great many materials for undertones, and found that they fall, in this respect, into three groups. In the middle stand those materials which furnish undertones, that is, the great majority of all substances in general On the one side are those substances which, as soon as the vibrations are pretty strong, give no resonance-tones, but merely an indeterminate noise ; to this group belong rolled plate metal and most kinds of glass. On the other side are those substances which, however strong the vibrations, always give the tone of the tuning-fork. I have found only one example of this, viz., the wood of mountain fir, in thin polished plates. It was natural to try the belly of a violin, which is mostly made of firwood, for undertones, and in this way form an idea as to the elasticity of the wood, on which the excellence of the instrument greatly depends. From the German violins I have examined, I have always obtained undertones; from the few authentic Italian violins accessible to me $I$ obtained, on the other hand, always the original tone. But I acknowledge that more abundant material is necessary for a decision of this question."

\section{THE DISRUPTIVE DISCHARGE OF ELEC-
TRICITY}

BY means of the following method we have been able to investigate the laws of the disruptive discharge of electricity of high potential-a subject of investigation which is the complement of that in which Drs. Warren de la Rue and Muiller have been simultaneously engaged. In making these experiments I have had the able co-operation in succession of Messrs. Salvesen, Connor, Stewart, Simpson, and Playfair.

The method essentially consists in connecting the prime conductor of the Holtz machine, not with the electrometer directly, but with an insulated spherical ball placed at some distance from an equal spherical ball, the latter being connected with the electrometer. The woodcut represents, in situ, the apparatus which was used in the case of the gases. The receiver of the air-pump, which has a rod capable of moving air-tight, was attached to one of the conductors of the Holtz machine in such a manner that the conductor and the rod formed one conducting system. Projecting from the plate of the air-pump was a short metal rod, which formed one conductor with the metallic parts of the air-pump, and, by means of a wire, with the uninsulated conductor of the Holtz machine. Electrodes of various forms were made to screw on to the ends of the rods. Of the two insulated brass balls one, A, was fixed; the other, B, could be moved along the connecting board. The wire joining $A$ to the collar of the receiver is insulated with gutta-percha. The electrometer in connection with B is one of Sir W. Thomson's divided ring reflecting electrometers.

When the potential of $\mathrm{A}$ is raised by driving the machine, the potential of $\mathrm{B}$ is also raised, and this goes on until a discharge takes place between the electrodes inside the receiver. Hence the maximum deflection of the spot of light from zero is an indication of the difference of potential of the two surfaces between which the spark passed immediately before the discharge. By breaking the contact between the conductors of the Holtz machine before beginning to turn the wheel, and, by turning slowly and uniformly, we were able to make the image of the

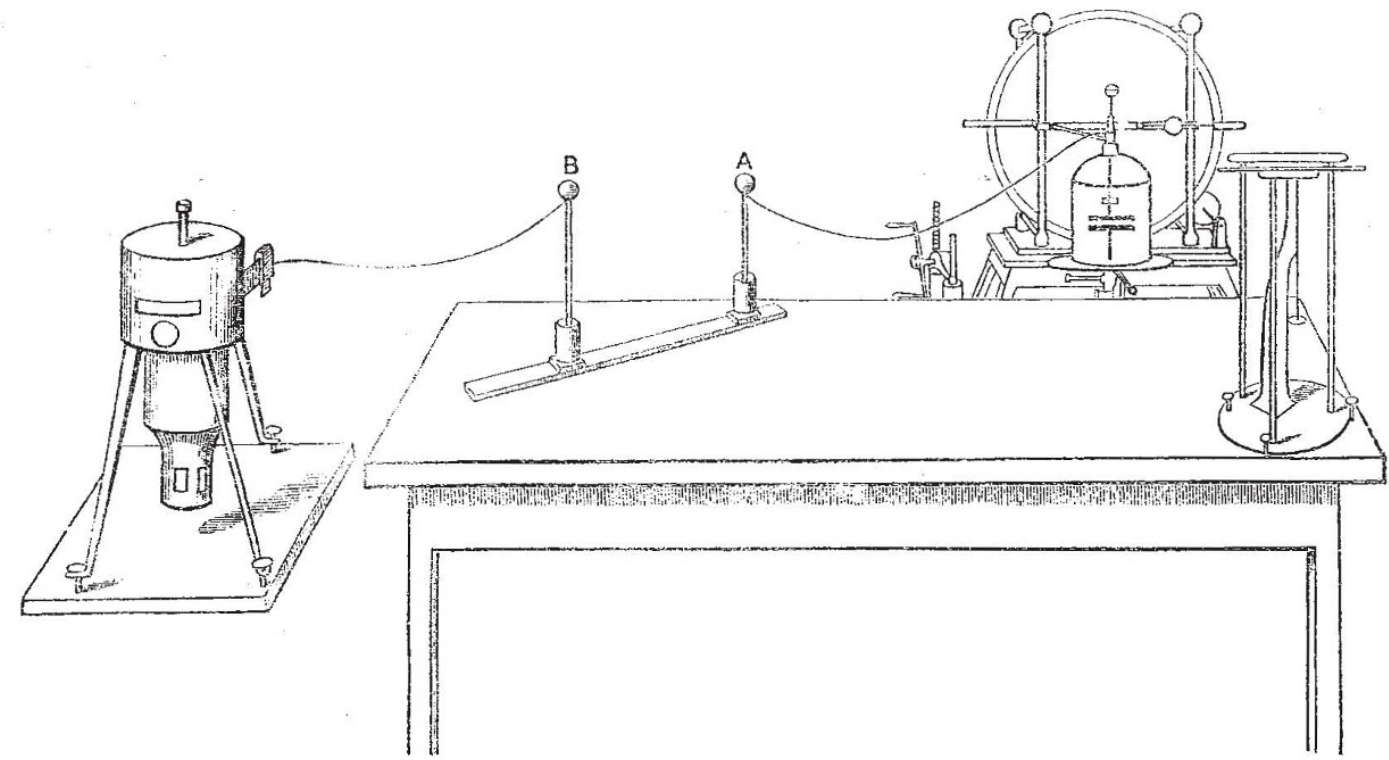

wire move up continuously, and to be at rest at the instant of discharge. After the discharge took place the image fell back to zero, or a point near zero. We always noted the position taken up by the image when the conductor of the machine was completely discharged.

The force resisting the deflection of the mirror is the action of two external magnets upon several small magnets fixed to the back of the mirror ${ }^{2}$

One great merit of our method is the rapidity with which observations can be made. Three readings were in general taken for each entry. The mean of these is very probably free from any error due to accidental variations in the passage of the spark. An extensive series of observations have been printed

I Abstract by the author of thesis for D.Sc. and other papers printed in the recently issued part of the Transactions of the Royal Society of Edinburgh. By Alexander Macfarlane, M.A., D.Sc.

2 Our rosults

lute electrometer represented on the table. in full in the Transactions of the Royal Society of Edinburgh. The following are the more important results :-

A spark was taken through air between plates at a constant distance, and the distance between the balls $\mathrm{A}$ and $\mathrm{B}$ varied. Let $V$ denote the induced potential, and $r$ the distance between the centres of $\mathrm{A}$ and $\mathrm{B}$; then the experimental curve obtained satisfies the equation-

$$
V=608 \mathrm{I} r^{-1}-42 \cdot 26
$$

for values of $r$ greater than 24 centimetres ;"but for less values of $r$ the function requires to be corrected by being multiplied by-

$$
\cdot 524+\cdot 02 r \text {. }
$$

Sparks were taken through air at the atmospheric pressure between parallel metal disks of 4 inches diameter for distances up to $I^{\cdot} 2$ centimetres. The function for $V$, the difference of potential in terms of $s$, the length of the spark is-

$$
V=66.94 \mathcal{V}\left\{s^{2}+\cdot 205 s\right\} \text {, }
$$

